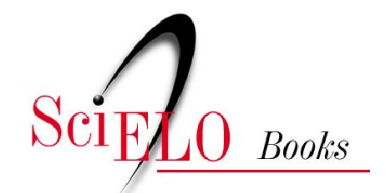

\title{
Um novo estado para uma nova sociedade
}

\author{
Fernando Henrique Cardoso
}

SciELO Books / SciELO Livros / SciELO Libros

CARDOSO, FH. Avança, Brasil: proposta de governo [online]. Rio de Janeiro: Centro Edelstein de Pesquisas Sociais, 2008. pp. 1-10. Um novo estado para uma nova sociedade. ISBN: 978-85-9966268-7. Available from SciELO Books $<\underline{\text { http://books. scielo.org }>\text {. }}$

\section{(1) $(0)$}

All the contents of this chapter, except where otherwise noted, is licensed under a Creative Commons Attribution-Non Commercial-ShareAlike 3.0 Unported.

Todo o conteúdo deste capítulo, exceto quando houver ressalva, é publicado sob a licença Creative Commons Atribuição Uso Não Comercial - Partilha nos Mesmos Termos 3.0 Não adaptada.

Todo el contenido de este capítulo, excepto donde se indique lo contrario, está bajo licencia de la licencia Creative Commons Reconocimento-NoComercial-CompartirIgual 3.0 Unported. 


\section{UM NOVO ESTADO PARA UMA NOVA SOCIEDADE}

Este documento apresenta as diretrizes do programa de governo com as quais se compromete o presidente Fernando Henrique Cardoso, se reeleito para um novo mandato. São diretrizes e metas ao mesmo tempo consistentes e ambiciosas. Consistentes porque se baseiam numa visão realista das possibilidades do país. Ambiciosas porque apontam para uma virada histórica no desenvolvimento da sociedade brasileira.

O sentido geral da mudança - o grande objetivo com o qual os demais se alinham - a é a inclusão dos excluídos. Não só como conseqüência do crescimento econômico, mas, principalmente, como utopia deliberadamente assumida pela sociedade, e possível de ser realizada no futuro próximo.

Incluir os excluídos não significa melhorar a vida de uma parcela de brasileiros em prejuízo dos demais. Nenhum setor precisa perder para que a inclusão se dê na escala desejada. É preciso, sim, que os frutos dessa nova etapa do desenvolvimento brasileiro sejam distribuídos de tal forma e com tal intensidade que permitam melhorar significativamente as condições de vida dos mais pobres. Para isso, é preciso vincular estabilidade e investimento produtivo; crescimento e geração de empregos; competitividade e universalização da educação fundamental; equilíbrio fiscal e melhoria das políticas sociais. Em uma palavra, simultaneamente, progresso material e progresso social.

O Plano Real deu início a essa virada, ao promover a estabilização econômica junto com a preservação do poder aquisitivo dos trabalhadores e a recuperação da renda da grande maioria que vinha sendo espoliada, anos a fio, pelo imposto inflacionário. As reformas empreendidas pelo governo Fernando Henrique estão preparando as bases institucionais e materiais para uma nova era de desenvolvimento do país. Agora, está ao alcance dos brasileiros e brasileiras fazer com que esse salto conduza efetivamente, mais do que a uma nova economia, a uma nova sociedade.

Isto supõe, além da ação eficaz do governo, intensa mobilização da própria sociedade em tomo do projeto comum de desenvolvimento com justiça e exercício pleno da cidadania.

Este projeto nasce do sentimento de indignação que as chagas da miséria e da desigualdade despertam, e de solidariedade para com suas vítimas. E tem por objetivo elevar o patamar de exercício da cidadania que já se faz presente, e ao qual as reformas políticas hão de dar expressão mais vigorosa.

Para tanto, haveremos de contar, como contamos nestes quatro anos, com a condução de uma liderança firme, com profundo conhecimento do Brasil e do mundo, a força da convicção no rumo a seguir, a experiência, o equilíbrio e a capacidade de diálogo para manter o país unido nesta grande travessia. Uma liderança acima de tudo democrática, com coragem para mudar e humildade para saber que, numa sociedade tão complexa, com interesses tão diversificados como a brasileira, as mudanças necessárias, ou virão pela via do diálogo, da persuasão, da negociação e do entendimento, ou desaguarão no impasse paralisador, que não poucas vezes vivemos no passado.

Por reconhecer que Fernando Henrique tem esse perfil de liderança, sua reeleição é a melhor garantia de que não haverá retrocessos e de que não deixaremos escapar a chance de entregar aos nossos filhos, no novo século, um Brasil mais próximo do país dos nossos sonhos e dos sonhos de nossos pais.

\section{DIRETRIZES BÁSICAS DO PROGRAMA DE GOVERNO}

\section{Mais quatro anos de desenvolvimento para todos}

A eleição de Fernando Henrique, em 1994, significou um voto de confiança do Brasil no Plano Real e na pessoa que liderou sua formulação e sua implantação, quando a inflação minava a economia, as instituições e o próprio futuro do país. 
Quatro anos depois, temos amplos motivos para confirmar esse voto. O compromisso do presidente de garantir o valor do Real foi rigorosamente cumprido. Graças a isso, sobre o terreno preparado pela estabilidade econômica e política, hoje floresce a confiança do Brasil em si próprio.

Estamos conseguindo estabilizar nossa economia em um quadro de turbulências como raras vezes se viu. O mundo está sendo sacudido por transformações econômicas, financeiras, políticas, sociais, culturais, tecnológicas e demográficas extraordinariamente rápidas e profundas, numa escala comparável à dos grandes momentos da história da humanidade.

A globalização, longe de marcar o "fim da história", é o começo de algo novo, um processo de mudança ainda em curso. Por isso mesmo, apresenta riscos e aumenta a incerteza sobre o futuro de cada país, de cada segmento da sociedade, de cada ser humano. Mas também oferece oportunidades, que precisamos saber aproveitar, para afirmarmos o Brasil como país e avançarmos mais rápido na realização das nossas aspirações a prosperidade e justiça social.

A história não caminha para trás. Não será com escapismos nem com propostas ultrapassadas que iremos promover o crescimento econômico, multiplicar as oportunidades de trabalho e conseguir mais bem-estar para todo o povo.

O desafio da integração soberana do Brasil nessa nova era requer idéias igualmente novas.

Reclama visão do futuro e coragem para realizar as grandes transformações na economia e na sociedade.

Exige um Estado com outro perfil, mais ágil, mais eficaz e mais forte em seus novos papéis.

Depende de uma presença competente, combativa e de firmes posições nas grandes discussões internacionais.

Só assim poderemos emergir da turbulência como um grande país do século XXI. Grande, não como potência com pretensões hegemônicas - que não temos -, mas como exemplo de sociedade pluralista, democrática, socialmente mais justa e mais igualitária.

Contamos, nesse percurso, com o capital de nossos enormes recursos naturais, da diversidade da nossa cultura, do vigor da nossa sociedade civil, da força da nossa jovem democracia e, sobretudo, do valor do nosso povo, combativo, alegre, tolerante e trabalhador.

Nosso desafio é, porém, maior do que o de outros países. Nossa estrutura produtiva é resultado de um esforço de industrialização ainda recente. Marcamos passo, anos e anos, tentando debelar a inflação. Apesar de estarmos entre as dez maiores economias do mundo, acumulamos ao longo dos anos uma imensa e vergonhosa dívida social.

A miséria e a fome são enfermidades que precisam ser banidas de nosso país. O contraste entre a ostentação de riqueza e a pobreza absoluta envenena a coesão da sociedade.

A indignação com esse estado de coisas cresce na mesma medida da confiança do Brasil em suas próprias forças. Mas a indignação, por si só, não move o mundo. Indignados, devemos ser capazes, governo e povo, de compartilhar o sonho de uma nova sociedade, e de juntos lutar para fazer desse sonho uma realidade. Sem ceder aos apelos da demagogia fácil, das promessas irresponsáveis, mas com horizontes claros, propósitos firmes, perseverança e continuidade na implementação das medidas.

A reeleição de Fernando Henrique representa para nós, da ampla aliança que a apóia, a certeza de que estaremos preparados - povo e governo - para enfrentar esse novo e fascinante desafio.

Nestes quatro anos, a administração do presidente Fernando Henrique empenhou-se em desenvolver um amplo conjunto de políticas para colocar o país no caminho da realização do seu potencial. 
Sustentou o Plano Real, controlando a inflação, acabando com a carestia e permitindo que mais de dez milhões de brasileiros se incorporassem ao consumo de bens privados e públicos.

Agiu em todas as frentes e em todas as regiões brasileiras para ampliar e modernizar a infraestrutura de transporte, energia e comunicações, preparando o país para uma nova etapa de crescimento.

Pôs em marcha uma profunda reforma do Estado e da administração pública federal.

Trabalhou intensamente, dentro e fora do Brasil, para aumentar o investimento produtivo no país, criando condições para a instalação de novas empresas em todo o território nacional.

Revolucionou a atuação do governo federal nas áreas de educação, assistência social, reforma agrária e qualificação profissional. Melhorou de forma significativa a atuação federal nas áreas de saúde, previdência social, crédito rural e apoio às micro e pequenas empresas, no campo e na cidade.

Atento ao florescimento cultural do país, aprimorou os mecanismos de incentivo à cultura, cujos recursos foram multiplicados por trinta.

Renovou a maneira de apoiar o desenvolvimento científico e tecnológico, elevando o investimento nesse setor.

Assegurou o pleno exercício da cidadania e promoveu intensa defesa dos direitos humanos.

Mas, tendo feito muito, aprendemos que ainda há muito por fazer.

É preciso avançar. O Brasil não quer, não pode e não irá voltar atrás.

Avançar para consolidar o Real, defendendo nossa moeda contra a especulação internacional, garantindo o fim da inflação, buscando o equilíbrio das contas públicas e o aumento da capacidade de poupança e de investimento.

Avançar para fazer o país crescer de forma sustentada e gerar oportunidades de trabalho, explorando ao máximo as possibilidades contidas nas condições internas e externas da nossa economia. Vamos duplicar nossas exportações e crescer com base na agricultura, nos investimentos industriais, nos serviços modernos, no turismo e na construção civil.

Avançar para desenvolver e consolidar a democracia na vida cotidiana de todos os brasileiros, promover os direitos civis, acabar com as discriminações, garantir a segurança dos cidadãos, numa guerra sem trégua contra toda forma de crime e de violência.

Avançar, sobretudo, na luta permanente contra a exclusão social, a fome, a pobreza e a desigualdade, realizando uma nova revolução nas políticas sociais e de transferência de renda.

Avançar com a serenidade que procede da experiência acumulada e com o entusiasmo renovado pela consciência do muito que ainda resta por fazer na construção de uma nova sociedade, neste novo século, da qual possamos nos orgulhar.

Uma sociedade mais igualitária, da qual se tenham erradicado a miséria e a fome, é a grande utopia que hoje temos possibilidade concreta de realizar no Brasil. Seremos capazes de realizá-la a médio prazo, se a isso nos dedicarmos desde já.

Imbuídos dessa determinação, o presidente Fernando Henrique e o conjunto de forças que o apóiam se apresentam ao povo brasileiro para disputar a oportunidade de servi-lo por mais quatro anos, e submetem ao debate público os quatro grandes objetivos e as principais metas de seu programa de governo para um novo mandato. 


\section{CONSOLIDAR A ESTABILIDADE ECONÔMICA}

O Plano Real reduziu a inflação aos mais baixos índices dos últimos cinqüenta anos, garantindo o poder de compra dos salários e a estabilidade do custo da cesta básica. Em consequiência, melhorou a renda média dos brasileiros, especialmente dos mais pobres.

Os efeitos sociais benéficos do fim da carestia não se esgotaram. Eles continuam a se fazer sentir na medida em que a estabilização alcança os preços de serviços públicos, aluguéis, serviços pessoais e bens de consumo antes sujeitos a fortes variações. Exemplo disso é a recente redução dos preços dos combustíveis, que beneficiará diretamente a base da sociedade, via menor custo dos transportes e de novas reduções no preço da cesta básica.

Que a estabilidade é um bem social de primeira necessidade ninguém se anima a questionar. Mas isto não basta. É preciso afirmar claramente que ela é uma conquista a ser permanentemente defendida e consolidada diante da instabilidade econômica internacional, das dificuldades do equilíbrio das contas públicas nos diferentes níveis de governo, das pressões estruturais derivadas do crescimento econômico e da própria necessidade de enfrentar a imensa dívida social brasileira.

Aqui não pode haver vacilações. O povo brasileiro já passou por muitos sacrifícios para saber que qualquer retrocesso no controle da inflação pode por a perder, mais do que o valor da moeda, a estabilidade da renda do próprio povo e as chances de desenvolvimento sustentado do país.

\section{Nenhuma promessa de prosperidade fácil deve nos iludir, nem desviar o futuro governo da determinação de impedir a volta da inflação e da carestia.}

Por isso, o presidente Fernando Henrique, se reeleito, atuará com firmeza para:

- avançar na reorganização do setor público, completando as reformas estruturais necessárias para facilitar o controle do volume e a melhora da qualidade do gasto público, e garantir o equilíbrio a médio e longo prazo das contas da previdência;

- combater os déficits orçamentários nos três níveis de governo, detendo o crescimento da dívida pública em relação ao produto interno, aliviando a pressão do setor público sobre a poupança privada e abrindo espaço para a redução continuada dos juros;

- simplificar o sistema tributário e reduzir o peso dos impostos sobre a produção, o investimento e a exportação;

- aprofundar a reestruturação do setor produtivo, levando adiante o programa de privatização e fortalecendo o Estado no papel de regulador e indutor do desenvolvimento;

- reconstruir o sistema de crédito nacional, orientando a atuação das instituições financeiras federais para as áreas produtivas e os setores sociais que delas mais necessitam e resgatando o papel dos bancos privados como agentes de crédito comercial;

- aumentar as exportações, perseguindo a meta de duplicá-las até 2002, não pela via enganadoramente fácil da desvalorização cambial, mas pela rota segura da redução do "custo Brasil" e dos ganhos consistentes de produtividade;

- consolidar o espaço econômico do Mercosul, promover a integração comercial com os demais países sul-americanos, defender os interesses do Brasil e dos demais países do Mercosul nas negociações para a eventual criação da ALCA, manter uma presença ativa e de firme defesa de nossas posições nos demais fóruns internacionais, combatendo o protecionismo comercial e propugnando pela criação de mecanismos multilaterais de defesa contra as turbulências do mercado financeiro globalizado. 


\section{PROMOVER O CRESCIMENTO ECONÔMICO SUSTENTADO, A GERAÇÃO DE EMPREGOS E DE OPORTUNIDADES DE RENDA}

Com a estabilidade da moeda, o Brasil voltou a crescer de forma regular e sustentada, apesar da turbulência externa e dos pontos de estrangulamento que se acumularam internamente ao longo de anos de estagnação da economia.

O Produto Interno Bruto aumentou mais de vinte por cento nos últimos cinco anos e a renda per capita, estagnada há quase um decênio, cresceu em média 2,6\% ao ano. A taxa de investimento é a maior dos últimos dez anos. A entrada líquida de investimentos diretos passou de menos de um bilhão de dólares em 1993 para um montante estimado em cerca de vinte bilhões em 1998.

A retomada do crescimento teve um impacto positivo sobre a geração de postos de trabalho. Cerca de três milhões de novos empregos foram criados entre 1992 e 1996. Só nas seis principais regiões metropolitanas, onde vive um de cada quatro brasileiros, mais de um milhão de empregos foram criados entre junho de 1994 e junho de 1998, apesar do movimento de interiorização da indústria.

Contudo, a expansão das oportunidades de trabalho foi muito modesta em relação às necessidades do país. Isto se deve em parte às medidas tomadas em 1995, e novamente em 1997, para defender o Real da especulação externa. E se deve em parte à tendência que atinge todos os países, em função da incessante incorporação de inovações tecnológicas que substituem o trabalho humano, bem como das novas formas de organização da produção em escala mundial.

Nossa população em idade de trabalhar estará crescendo cerca de dois por cento ao ano nos próximos anos. Além dos jovens em busca do primeiro emprego, mais mulheres de todas as idades passaram e continuaram passando a procurar uma ocupação fora de casa.

O Brasil terá de criar 7,8 milhões de postos de trabalho até 2002 para absorver esses novos contingentes. A resposta a esse imenso desafio passa necessariamente pela aceleração do crescimento do país.

As perspectivas para tanto são amplamente favoráveis - e não por acaso. Os avanços alcançados pelo primeiro governo do presidente Fernando Henrique - as reformas estruturais, as privatizações, o saneamento do sistema bancário, o resgate da credibilidade e a nova projeção internacional do Brasil, os investimentos em infra-estrutura, a recuperação da capacidade de atuação dos bancos federais, a melhoria na área educacional e de qualificação - prepararam a economia brasileira para uma nova arrancada de crescimento.

Mas não basta crescer. É preciso distribuir os frutos do crescimento à medida que eles surgem, o que significa, concretamente: aumento sustentado do valor médio dos salários e da massa salarial. Isto depende da melhoria da qualidade e da produtividade dos empregos existentes e, ao mesmo tempo, da geração de novos empregos. O que por sua vez supõe, mais do que a simples aceleração do crescimento econômico, uma nova forma de crescimento, que integre e articule dinamicamente a extraordinária variedade de regiões, setores e espécies de unidades produtivas da economia brasileira.

Um país com a rara diversidade e as dimensões continentais do Brasil não precisa se resignar a taxas de crescimento medíocres, nem muito menos a taxas altas de desemprego.

Por isso, o presidente Fernando Henrique, se reeleito, desenvolverá uma estratégia de desenvolvimento voltada para:

- adensar a ocupação do território nacional ao longo dos eixos de desenvolvimento definidos pelo atual governo no programa Brasil em Ação, indicando as possibilidades dinâmicas de investimento privado em cada região e articulando-as com as ações do setor público, tanto no que se 
refere à infra-estrutura econômica como aos investimentos sociais;

- ampliar e diversificar os programas de apoio aos micro e pequenos produtores rurais e urbanos, combinando facilidades de acesso ao crédito, tecnologia e canais de comercialização e estimulando as diversas formas de cooperação e parceria entre pequenas e grandes empresas, ao longo das cadeias produtivas;

- estimular setores que se caracterizam por ser ao mesmo tempo competitivos e intensivos em mão-de-obra, a exemplo de telecomunicações, indústria cultural, turismo, construção civil, fruticultura irrigada e pesca;

- expandir a oferta de empregos na prestação de serviços sociais - educação, saúde, assistência social, assistência técnica à agricultura familiar - por intermédio do setor público e de parcerias com a sociedade civil;

- intensificar as ações de fomento a cargo de agências como o BNDES e o Banco do Nordeste, visando à modernização da indústria brasileira e à reconversão de segmentos defasados, promovendo, em especial, a reciclagem profissional dos trabalhadores desses setores;

- elevar a capacitação nacional em ciência e tecnologia, mediante a articulação de investimentos públicos e privados e de apoio às atividades de pesquisa e desenvolvimento - P\&D, dentro e fora das. universidades;

- incorporar de forma sistemática a dimensão ambiental a todos os programas e projetos econômicos, em consonância com os compromissos da Agenda 21, buscando de maneira criteriosa e sustentável o melhor aproveitamento dos recursos naturais de cada região do país;

- elevar a escolaridade média do trabalhador brasileiro, dando continuidade, em articulação com os estados e municípios, às ações voltadas para a melhoria da qualidade e do aproveitamento no ensino público fundamental;

- ampliar as oportunidades de acesso dos jovens ao ensino médio, alcançando a meta de dez milhões de alunos, e elevar a qualidade da educação, implantando a reforma curricular já definida e melhorando as condições materiais das escolas;

- triplicar a matrícula no ensino técnico de nível médio, em especial nas novas áreas de geração de emprego, e aumentar a oferta de qualificação profissional, incluindo, entre outros, recursos do Fundo de Amparo ao Trabalhador - FAT, requalificando dezessete milhões de trabalhadores nos próximos quatro anos.

\section{ELIMINAR A FOME, COMBATER A POBREZA E A EXCLUSÃO SOCIAL, MELHORAR A DISTRIBUIÇÃO DE RENDA}

Um dos resultados mais importantes da estabilidade econômica foi a eliminação do imposto inflacionário e a elevação do poder de compra do salário mínimo e de milhões de benefícios previdenciários. Isso permitiu reduzir o número de famílias indigentes e pobres, e incorporar milhões de brasileiros ao mercado de consumo.

Nos últimos quatro anos, além de contribuir decisivamente para manter acima de vinte por cento do PIB o gasto total do país com programas sociais, o governo do presidente Fernando Henrique revolucionou a prestação dos serviços sociais básicos de responsabilidade pública.

Deu, de fato, prioridade ao ensino fundamental, criando o fundo de valorização do professor e iniciando um grande esforço para colocar todas as crianças de sete a quatorze anos na escola: hoje, 95\% das crianças nesta faixa etária estão matriculadas. 
Atualizou o marco normativo do sistema educacional, com a Lei de Diretrizes e Bases e o Plano Nacional de Educação, reorganizou o Ministério da Educação e assegurou programas de ensino à distância, merenda e transporte escolar.

Criou um amplo programa de equipes de médicos de família - 3.500 equipes $-\mathrm{e}$ de agentes comunitários de saúde - 100 mil agentes.

Reduziu a mortalidade infantil - indicador-síntese das condições de vida de um povo.

Dinamizou o programa de saúde da mulher e criou um dos melhores serviços de atendimento aos pacientes de Aids.

Revolucionou a qualificação profissional.

Realizou o maior programa de reforma agrária em execução no mundo, superando tudo o que se fez no Brasil em qualquer outro período.

Melhorou de forma substancial o valor real dos benefícios previdenciários dos aposentados mais pobres.

Retomou, dentro de novas regras, o financiamento federal à compra e construção de moradias e a obras de saneamento.

Conduziu um grande esforço, não só para investir mais na área social porém, sobretudo, para gastar melhor, aprimorando a gestão dos programas sociais.

Focalizou e concentrou ações nos municípios e grupos sociais mais carentes, por intermédio do programa Comunidade Solidária a semente de uma promissora parceria entre o governo e a população.

Mobilizou a sociedade e instituiu uma nova forma de política assistencial, rompendo com o clientelismo e o fisiologismo.

Ainda assim, a dívida social brasileira continua imensa e moralmente inaceitável. A experiência de governo, longe de arrefecer nossa indignação com esse estado de coisas, nos ensinou que nessa frente de batalha, em especial, devemos - e podemos - avançar mais.

Se mais de dez milhões de brasileiros superaram a linha da pobreza absoluta graças ao Plano Real, isto só nos estimula e aumenta a determinação de continuar travando uma guerra sem quartel contra a exclusão.

Resgatar da indigência mais de cinco milhões de famílias, eliminar a fome e a exploração do trabalho infantil, assegurar o acesso dos brasileiros mais pobres a serviços públicos de boa qualidade: eis a grande tarefa que temos pela frente para tomar realidade o sonho de uma sociedade mais justa e mais igualitária. Para acelerar o passo do país na direção dessa utopia, hoje finalmente possível, o presidente Fernando Henrique, se reeleito, articulará múltiplas ações, dos diferentes níveis do governo e da sociedade civil, de acordo com as seguintes diretrizes:

- aumentar o impacto distributivo do gasto público em programas sociais. Eliminar distorções e privilégios e melhorar a gestão dos programas, levando em conta a diversidade de situações dos beneficiários. Gastar melhor para poder investir mais no combate à fome e à pobreza;

- completar e implementar a reforma da Previdência Social votada pelo Congresso, para assegurar a universalidade do direito à cobertura básica pelo INSS - hoje e no futuro - preservando o valor dos benefícios e permitindo a progressiva elevação do seu piso;

- desenvolver uma política nacional de transferência de rendas, assegurando e conjugando os diferentes programas federais existentes - aposentadoria rural, seguro-desemprego, benefícios de prestação continuada, como renda mensal vitalícia, renda mínima para idosos e portadores de 
deficiência, benefícios do PIS-PASEP;

- aumentar o impacto distributivo da massa de recursos transferidos, coibindo as fraudes e os abusos e melhorando, sempre que possível, a focalização dos programas. Implementar, de acordo com essa política, o apoio a programas estaduais e municipais de bolsa-escola, conforme lei já sancionada pelo presidente Fernando Henrique;

- universalizar - ampliando ao máximo a cobertura - e melhorar a qualidade dos serviços sociais básicos de responsabilidade pública, incluindo pré-escola e ensino fundamental - com maior número de horas das crianças na escola; alfabetização de jovens e adultos; saúde básica e preventiva - com ênfase na saúde da mulher, na ampliação das equipes de saúde da família e do número de agentes comunitários; assistência social a crianças, idosos e portadores de deficiência; segurodesemprego, requalificação profissional e recolocação no mercado de trabalho;

- tornar exemplar o atendimento ao público nos serviços sob supervisão direta do governo federal, como o INSS, os Correios e Telégrafos, o Banco do Brasil e a Caixa Econômica Federal, investindo na qualificação dos funcionários, recuperação das instalações e informatização dos procedimentos;

- intensificar as ações de combate à pobreza e melhoria da qualidade de vida na periferia das médias e grandes cidades, em articulação com estados e municípios. Facilitar o acesso a lotes urbanizados e regularizados e a aquisição ou construção da casa própria, consolidando a oferta de financiamento por intermédio da Caixa Econômica Federal. Expandir e melhorar os serviços de infra-estrutura urbana: universalizar o abastecimento de água potável, energia elétrica e a coleta de lixo; ampliar a cobertura da rede de esgotos; melhorar o transporte de massa mediante ação do BNDES. Expandir a oferta e baratear o custo dos telefones, nos termos dos contratos de concessão das empresas de telecomunicações privatizadas;

- dar acesso a terra, crédito, tecnologia e canais de comercialização a quatro milhões de famílias de pequenos proprietários, assentados e trabalhadores rurais sem terra. Permitir a estabilização, diversificação e ampliação de suas fontes de renda, promovendo sua integração às cadeias produtivas agroindustriais. Melhorar as condições de vida do Brasil rural por meio de uma política integrada de moradia, transporte, eletrificação, telefonia, além do acesso à educação básica, saúde e qualificação profissional. Dar prosseguimento à reforma agrária via assentamentos, outras formas de acesso à terra - e ir além, criando um novo mundo rural;

- resolver de forma decisiva o problema da convivência da população nordestina com as secas periódicas, ampliando e articulando os investimentos na infra-estrutura econômica e social da região. Generalizar o acesso aos grandes avanços conseguidos nos últimos anos no manejo de recursos hídricos e nas técnicas agrícolas para o Semi-árido;

- multiplicar as diversas experiências de desenvolvimento local integrado e sustentado, tais como a do programa Comunidade Solidária - que focaliza um conjunto básico de programas sociais nas áreas geográficas e grupos sociais mais carentes - as do Banco do Nordeste do Brasil e da Agenda 21 Local. Aproveitar as potencialidades locais para aumentar as oportunidades de trabalho e de obtenção de renda da população, mediante ações integradas de desenvolvimento;

- ampliar as ações do governo federal e incentivar a articulação das iniciativas de estados, municípios e organizações da sociedade civil que permitam eliminar a fome do país. Apoiar a melhoria das condições de produção, estocagem, transporte e comercialização de alimentos em geral e estimular a produção e o consumo de alimentos com maior poder nutritivo, por intermédio dos programas de merenda escolar e distribuição de cestas básicas, entre outros meios;

- combater o trabalho infantil e erradicá-lo quando prejudicial, escravo, penoso e degradante. Identificar as atividades que exploram crianças e punir os responsáveis. Garantir a essas crianças 
ensino público gratuito e de boa qualidade. Mediante apoio às iniciativas dos estados e municípios, fornecer bolsa-escola às suas famílias, bem como serviços de acompanhamento escolar, atividades culturais e de lazer fora do horário de aulas. Apoiar a expansão da pré-escola e cumprir a meta de colocar e manter na sala de aula todas as crianças de sete a quatorze anos.

\section{CONSOLIDAR E APROFUNDAR A DEMOCRACIA, PROMOVER OS DIREITOS HUMANOS}

O Brasil reencontrou o caminho da democracia depois de mais de duas décadas de autoritarismo. Hoje, temos eleições regulares e livres para todos os níveis de governo, com elevada participação eleitoral. Temos um número sem paralelo de organizações da sociedade civil com viva participação nos mais variados setores da vida nacional. Temos uma imprensa diversificada, livre e combativa.

O governo do presidente Fernando Henrique atuou vigorosamente para consolidar e fortalecer essas instituições democráticas.

Manteve relações respeitosas e de intenso diálogo com o Congresso Nacional e o Poder Judiciário.

No âmbito do Executivo, fortaleceu os diversos canais já existentes e criou novos mecanismos de interlocução entre o governo e a sociedade civil.

Dinamizou o processo de descentralização, valorizando as atividades de estados e municípios, modificando os procedimentos de transferência de recursos federais nas áreas de educação - Fundo de Valorização do Magistério; saúde - Piso de Assistência Básica; e assistência social.

Desenvolveu, em estreita cooperação com organismos da sociedade civil, o Plano Nacional de Direitos Humanos, e promoveu junto ao Congresso Nacional importantes avanços na legislação pertinente.

Começou a reaparelhar a Polícia e a Receita Federal, fechou o cerco à lavagem de dinheiro e criou uma secretaria especial, sob supervisão direta da Presidência da República, para enfrentar os graves problemas relacionados ao tráfico de drogas.

Todos esses avanços não disfarçam, antes tomam mais visíveis os sintomas persistentes do nosso atraso político e da insegurança em que vivem nossos cidadãos.

Nossas instituições representativas ainda são frágeis diante das mazelas do elitismo, do mandonismo local e do clientelismo, assim como do corporativismo exacerbado e da influência indevida dos grandes conglomerados econômicos. As pressões da sociedade civil, embora vigorosas, se esterilizam freqüentemente pelo emperramento da burocracia estatal. A sede de justiça da sociedade esbarra na desorganização dos órgãos de segurança e dos tribunais, o que conduz à impunidade.

Tanto quanto os vícios das instituições, a baixa densidade da cultura cívica democrática agrava os sentimentos de desconfiança e rejeição do povo em relação à atividade política. Num plano mais profundo, por isso mesmo mais grave, os flagelos da violência e das drogas denunciam a escassez de coesão social cimentada pela crença em valores comuns, mais do que pela ação coercitiva do Estado.

Esse quadro não nos desanima. Antes, reforça nosso compromisso com a democracia enquanto padrão de convivência civilizada. Democracia não apenas no plano formal das instituições, mas no relacionamento cotidiano entre o poder público e quem o sustenta, de um lado, e entre as pessoas, seja qual for sua condição social, de outro. Nosso compromisso aponta para novos e mais arrojados avanços na conquista dos requisitos institucionais, culturais e morais para o pleno exercício da 
cidadania por todos os brasileiros.

Queremos um Brasil mais justo e solidário, não apenas nos índices de bem-estar material, mas na capacidade de despertar em cada um de seus filhos o sentimento de pertencer e de ter amparo, vez e voz na sua comunidade, enfim, de participar nos destinos do país. Só isto mantém acesa a esperança de que as dificuldades do presente não são sacrifício inútil, mas parte do esforço comum por um amanhã melhor - algo que só se conquista duradouramente na democracia e pela democracia. Mais precisamente, pela radicalização da democracia, de forma que a disposição e os meios de participar alcancem a base da sociedade.

Por isso, o presidente Fernando Henrique, se reeleito, tratará de:

- promover o debate, pelo Congresso Nacional e pela sociedade, de reformas que revigorem nossas instituições representativas, fortalecendo os partidos e tomando mais nítidas e transparentes as relações do eleitorado com seus representantes em todos os níveis;

- aprofundar a reforma da administração pública federal, transformando-a para aumentar o desempenho e o controle público. Valorizar o servidor público, estimulando as carreiras, intensificando a qualificação profissional, premiando o desempenho e o mérito;

- levar adiante a descentralização das ações de governo no âmbito da Federação, aprimorando os mecanismos de integração programática entre a União, estados e municípios, em direção a um federalismo cooperativo;

- multiplicar as formas de parceria do governo com a sociedade civil, fortalecendo as experiências bem-sucedidas dos conselhos consultivos e das comissões nacionais no âmbito federal, entre outras;

- incentivar a participação comunitária e a solidariedade social em suas múltiplas formas, tanto no controle social das instituições públicas e privadas, como na filantropia e no serviço civil voluntário;

- apoiar as atividades artísticas e culturais, em toda a sua extraordinária diversidade, enquanto dimensão do talento criador e da vida coletiva, bem como expressão da identidade nacional;

- reforçar a autonomia e a liberdade sindicais, apoiando medidas que favoreçam o aumento da representatividade das organizações, o fortalecimento da negociação coletiva e da concertação social;

- intensificar, por intermédio do Programa Nacional de Direitos Humanos, o combate a todas as formas de discriminação, do mesmo modo que as ações afirmativas em favor de minorias e maiorias discriminadas, como as mulheres, os negros e os índios;

- intensificar o combate às drogas, em especial ao tráfico e aos mecanismos de lavagem de dinheiro, e coordenar ações com os estados para a modernização das suas polícias;

- estimular e apoiar reformas do Judiciário, visando torná-lo mais ágil e acessível a todos os cidadãos.

Para levar a cabo esse ambicioso sonho de construir uma sociedade livre, democrática, justa e solidária, o Brasil deve ter presença atuante no cenário mundial, como nação livre e soberana, desenvolvendo uma política externa competente e ativa, em defesa de seus legítimos interesses, promovendo o diálogo entre todos os povos e defendendo a paz mundial. 